\title{
Determinants of Compliance in a Cluster Randomised Controlled Trial on Screening of Breast and Cervix Cancer in Mumbai, India
}

\author{
1. Compliance to Screening
}

\author{
Ketayun Dinshaw Gauravi Mishra Surendra Shastri Rajendra Badwe \\ Rajendra Kerkar Subhash Ramani Meenakshi Thakur Pallavi Uplap \\ Anagha Kakade Subhadra Gupta Balasubramanian Ganesh
}

Tata Memorial Hospital, Mumbai, India

\section{Key Words}

Screening $\cdot$ Compliance $\cdot$ Randomised controlled trial $\cdot$

Breast cancer $\cdot$ Cervix cancer

\begin{abstract}
Objectives: This study aims to investigate the efficacy of screening by low-cost technology in down-staging and reducing mortality due to breast and cervix cancer. Methods: The present trial is a community-based, cluster randomised controlled cohort study on screening for breast and cervix cancers (clinical breast examination and visual inspection of the cervix after application of $4 \%$ acetic acid). Univariate and multivariate logistic regression analyses are conducted to identify the predictors of participation in screening. Results: The average compliance is 71.43 and $64.93 \%$ for breast and cervix cancer screening, respectively, with the highest compliance in round 1. At the end of 3 screening rounds, 94 and $84 \%$ of the eligible women were screened at least once for breast and cervix cancer, respectively. Younger women, women from other than Hindu and Muslim communities, school level-educated women, women belonging to lowerincome families, Marathi-speaking women, married women and women who had previously consulted for any breast or gynaecological complaints had higher compliance to par-
\end{abstract}

ticipation in screening. Conclusions: Good compliance rates to screening have been demonstrated in the trial, reflecting acceptance of the study by the society, which has implications while translating the trial into a programme.

Copyright $\odot 2008$ S. Karger AG, Basel

\section{Introduction}

Cervix cancer accounts for 126,000 , breast cancer for 83,000 new cases every year in India. These cancers are responsible for over $50 \%$ of the cancer burden among women $[1,2]$. Pap smear for the early detection of cervix cancer and mammography for the early detection of breast cancer are well-established strategies in developed countries. Unfortunately, we are unable to provide the same strategies to our people due to absence of trained manpower, lack of infrastructural facilities and issues related to quality assurance and logistics. This, however, does not deter us from making efforts to develop and establish cancer control programmes using simple technological methods and strategies for the economically disadvantaged people. The characteristics of visual inspection of the cervix after application of $4 \%$ acetic acid (VIA) as a screening test for cervical cancer has been evaluated

\section{KARGER}

Fax +4161306 1234 E-Mail karger@karger.ch www.karger.com (c) 2008 S. Karger AG, Basel

0030-2414/07/0734-0145\$23.50/0

Accessible online at:

www.karger.com/ocl
Mishra Gauravi, MD, DPH, DHA

Department of Preventive Oncology, 5th Floor, Annexe Bldg., R. No. 8

Tata Memorial Hospital, E. Borges Marg, Parel

Mumbai 400 012, Maharashtra (India)

Tel. +91 222415 7532, Fax +91 222410 1656, E-Mail gauravi2005@yahoo.co.in 
in several cross-sectional studies and reported to be satisfactory [3-5]. Screening by clinical breast examination (CBE) can be potentially as effective as screening by mammography [6], and the only randomised trial which compared CBE with CBE plus mammography was unable to demonstrate any added benefit of mammography over CBE alone [7].

There is no organised cancer screening programme in India at present. In the future, if we plan to incorporate sustainable organised community outreach screening services as part of the National Cancer Control Programme, the identification of factors determining participation and realistic estimate of the participation anticipated from the beneficiaries is essential. No screening programme can be undertaken if the community refuses to accept it at any stage.

The present trial is a community-based, randomised controlled screening trial being undertaken among 150,000 women of low socioeconomic status residing in the slums of Mumbai, India, for the early detection of breast and cervical cancers. It investigates the efficacy of low-cost techniques, namely well-planned health education programmes (HEP), VIA and CBE, conducted by trained primary health workers (PHW), in reducing disease burden in the form of down-staging and reduction of mortality due to cervix and breast cancers. This trial was initiated in 1998 and is expected to be completed by December 2015. The trial was approved by the Institutional Review Board of the Tata Memorial Hospital, which is registered with the Office for Human Research Protections at the US Department of Health and Human Services and possesses Federalwide Assurance. The present paper presents the results of an interim analysis conducted for the study period from 1998 to September 2005, focusing mainly on the determinants of compliance to screening. This paper discusses the participation rates, the factors determining participation, measures for improving participation and the implications of incorporating community-based screening activity for early detection of common cancers as part of the National Cancer Control Programme.

\section{Materials and Methods}

\section{Study Design}

This is a cluster randomised controlled cohort study on the screening of breast and cervical cancer using a low-cost technology approach. The study design is shown in figure 1 . In the intervention arm the women were given information about the trial and those willing to participate voluntarily signed an informed consent form and were then invited to participate in the HEP followed by screening for breast cancer by $\mathrm{CBE}$ and screening for cervix cancer by VIA. Women from the control arm were similarly invited to participate in the trial and those compliant signed an informed consent form and were enrolled into the trial. These women were given HEP in the first round.

Time Period

The trial is designed for women in the intervention clusters to receive 4 rounds of health education and screening at an interval of 24 months, followed by 4 rounds of active surveillance at 24month intervals for reporting incidence and mortality due to breast and cervix cancers. Similarly, the design involves women in control clusters to receive 1 round of health education followed by 7 rounds of active surveillance at an interval of 24 months for reporting incidence and mortality due to breast and cervix cancers. The trial involves 16 years of field work in each cluster. However, since field work in the intervention and control clusters 6-10 was initiated 2 years later than in the intervention and control clusters $1-5$, the entire trial duration will be 18 years (started in 1998 and expected to be completed by 2015).

\section{Selection of Clusters and Cluster Randomisation}

Twenty slum clusters from Mumbai were selected by singlestage simple random sampling technique. These 20 clusters were then randomly assigned to the intervention and control arms. Thus, there were 10 intervention clusters (IC $1-10, \mathrm{n}=75,360$ ) and 10 control clusters (CC $1-10, n=76,178)$, each with an average sample size of approximately 7,500. The sociodemographic variables of eligible women enrolled in the intervention and control clusters are presented in table 1 . This table shows that randomisation was successful in the clusters, ensuring equivalence of the subjects with respect to sociodemographic variables in the intervention and control arms.

\section{Inclusion Criteria for Women in the Study}

Women between the ages of 35 and 64 years, living in the selected clusters for more than 1 year, without any previous history of breast or cervix cancer or any other form of malignancy, were included in the study.

\section{Field Work Strategy}

Initially, medical social workers (MSW) developed rapport with the social, religious and other opinion leaders of the community. A baseline household survey was then carried out in the selected clusters for brief sensitisation and enlistment of eligible women. Intricate area maps were prepared, locating each house in the cluster. The MSW went from door to door and invited eligible women to participate in the trial and introduced the informed consent form which was available in the local language. The women signed or put their left hand thumb impression on the form. Another woman from the same community was invited to witness the procedure and was requested to sign as a witness. The MSW then personally invited women on the appointed days to attend the screening camps, which were temporarily set up at conveniently located places within the cluster. At the camp, the MSW conducted HEP in both arms, covering risk factors, signs and symptoms, methods of early detection as well as treatment modalities for breast and cervical cancers. They also educated the women regarding breast self-examination. The MSW recruited 
Fig. 1. Flow chart of study design: cluster selection, randomisation, screening rounds, surveillance, referral and treatment. SRS = Simple random sampling; $\mathrm{PHW}=$ primary health worker; TMC = Tata Memorial Centre; BMC = Brihanmumbai Municipal Corporation.

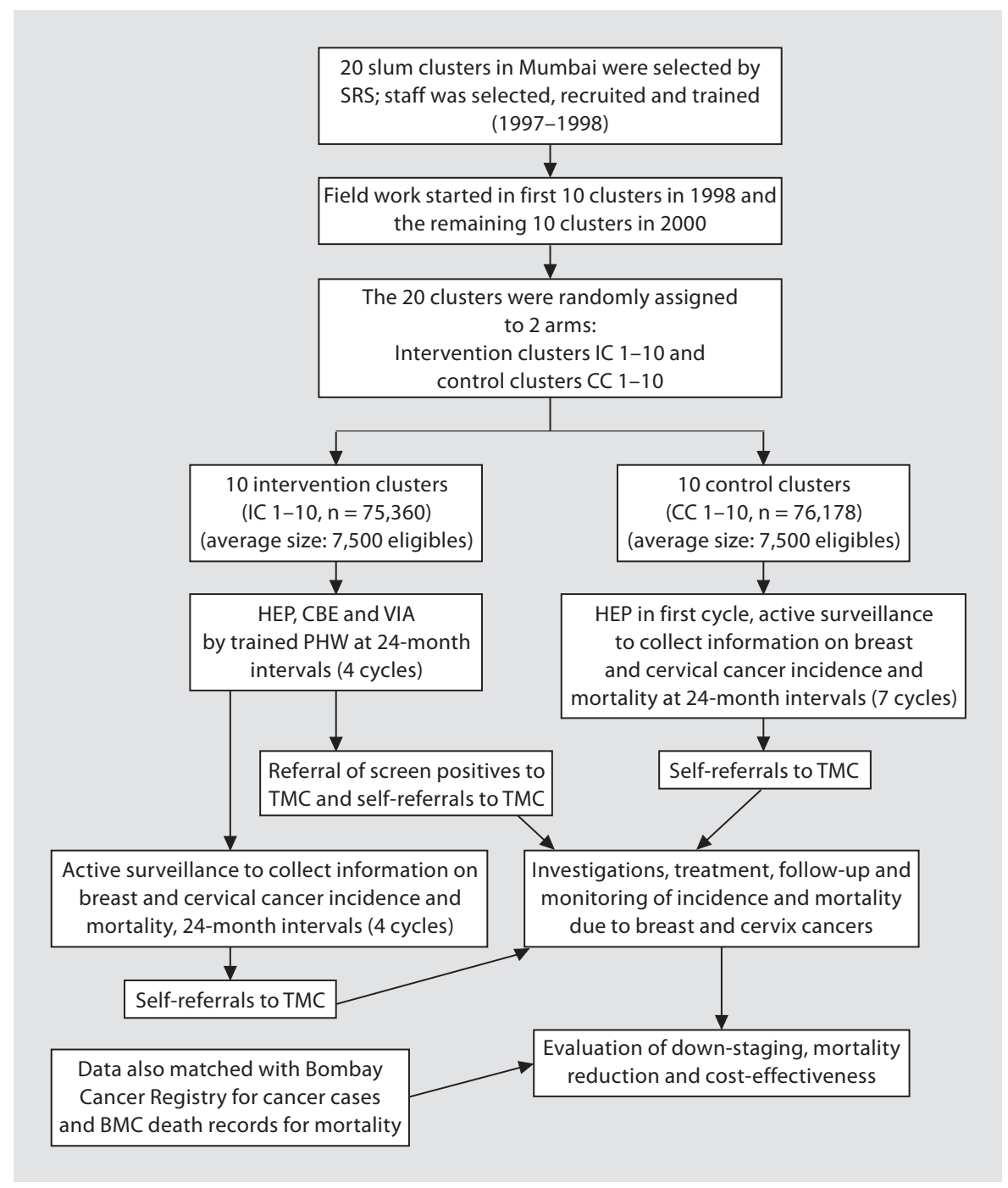

for this trial are graduates. They were given intensive training for a period of 4 weeks for delivering standard HEP, conducting household surveys, introducing the consent forms, counselling and follow-up communication. After the HEP, women in the intervention arm were invited to participate in breast and cervix cancer screening. The PHW conducted screening for breast cancer by CBE and for cervix cancer by VIA. The PHW recruited for the trial have tenth-grade education. They were given intensive training for 4 weeks, to perform CBE according to the modified version of the Canadian National Breast Screening Study protocol [8] and to perform VIA according to the IARC manual and chart [9]. The PHW and MSW are given 1-week annual refresher training. A trained [8-10] medical officer randomly reexamines $5 \%$ of the women examined by the health workers for quality check and records her findings separately.

In the active surveillance rounds, door-to-door surveys are carried out for recording the incidence or mortality due to breast and cervix cancers. The same procedures of community rapport building, baseline survey, preparation of road maps and commu- nity-based group health education were followed in the control arm. The eligible women from the control arm, however, were not invited for screening. Women in both arms are provided with colour-coded project identity cards with the information that they could approach Tata Memorial Hospital with this card in case they develop any symptoms of breast or cervix cancer.

\section{Three-Way Data Linkage}

There is a three-way data linkage in this study. Primary data collection for incidence and mortality through trained social workers is done in both arms. These records are then matched with the Mumbai Municipal Death Records and Mumbai Cancer Registry data to ensure completeness of records of death and of breast and cervix cancer cases, respectively.

\section{Sample Size Calculation}

We enrolled 75,360 and 76,178 women in the intervention and control arms, respectively. After adjusting for intracluster correlation (intracluster correlation and design effect is 0.000085477 
Table 1. Distribution by important sociodemographic variables at entry

\begin{tabular}{|c|c|c|}
\hline Variables & Intervention & Control \\
\hline Total & 75,360 & 76,178 \\
\hline \multicolumn{3}{|l|}{ Age groups } \\
\hline $35-39$ years & $22,718(30.22)$ & $22,832(30.00)$ \\
\hline $40-44$ years & $17,311(23.03)$ & $17,244(22.66)$ \\
\hline $45-49$ years & $14,183(18.86)$ & $14,111(18.54)$ \\
\hline $50-54$ years & $9,422(12.53)$ & 9,564 (12.57) \\
\hline $55-59$ years & $6,049(8.05)$ & $6,127(8.05)$ \\
\hline 60-64 years & $5,494(7.31)$ & $6,218(8.17)$ \\
\hline Mean age $\mathrm{l}^{1}$ & $44.84(7.86)$ & $44.92(8.01)$ \\
\hline \multicolumn{3}{|l|}{ Education } \\
\hline Literate & $3,104(4.14)$ & $3,661(4.82)$ \\
\hline Illiterate & $26,408(35.18)$ & $27,136(35.73)$ \\
\hline School & $42,198(56.23)$ & $41,345(54.44)$ \\
\hline High school and above & $3,340(4.45)$ & $3,806(5.01)$ \\
\hline \multicolumn{3}{|l|}{ Income per month } \\
\hline$<500$ rupees & $35,394(47.19)$ & $34,472(45.40)$ \\
\hline $500-1,000$ rupees & $34,949(46.59)$ & $37,156(48.93)$ \\
\hline$>1,000$ rupees & $4,667(6.22)$ & $4,307(5.67)$ \\
\hline \multicolumn{3}{|l|}{ Occupation } \\
\hline Housewife & $66,490(88.60)$ & $69,860(91.93)$ \\
\hline Service & $2,112(2.81)$ & $1,957(2.58)$ \\
\hline Manual labour & $4,718(6.29)$ & $3,083(4.06)$ \\
\hline Self-employed & $1,728(2.30)$ & $1,089(1.43)$ \\
\hline \multicolumn{3}{|l|}{ Religion } \\
\hline Hindu & $58,449(77.89)$ & $60,035(79.02)$ \\
\hline Muslim & $9,746(12.99)$ & $8,653(11.39)$ \\
\hline Others & $6,844(9.12)$ & $7,284(9.59)$ \\
\hline \multicolumn{3}{|l|}{ Language } \\
\hline Marathi & $42,704(56.87)$ & $40,558(53.35)$ \\
\hline Hindi & $12,883(17.15)$ & $15,251(20.06)$ \\
\hline Others & $19,508(25.98)$ & $20,208(26.58)$ \\
\hline \multicolumn{3}{|l|}{ Marital Status } \\
\hline Unmarried & $295(0.40)$ & $454(0.60)$ \\
\hline Married & $61,582(82.59)$ & $62,048(82.62)$ \\
\hline Widowed & $12,289(16.48)$ & $12,301(16.38)$ \\
\hline Divorced & $393(0.53)$ & $302(0.40)$ \\
\hline \multicolumn{3}{|l|}{ Menstrual status } \\
\hline Premenopausal & $40,360(53.78)$ & $40,913(53.85)$ \\
\hline Postmenopausal & $32,841(43.76)$ & $33,456(44.04)$ \\
\hline Perimenopausal & $1,844(2.46)$ & $1,601(2.11)$ \\
\hline Mean age at menarche, years ${ }^{1}$ & $13.79(1.26)$ & $13.85(1.24)$ \\
\hline Mean age at menopause, years ${ }^{1}$ & $43.36(4.96)$ & $43.62(4.87)$ \\
\hline Mean age at marriage, years ${ }^{1}$ & $17.99(3.89)$ & $17.85(3.82)$ \\
\hline Mean age at first child birth, years ${ }^{1}$ & $20.82(3.70)$ & $20.74(3.61)$ \\
\hline Average number of children ${ }^{1}$ & $3.58(1.61)$ & $3.56(1.61)$ \\
\hline \multicolumn{3}{|l|}{ History of breast feeding } \\
\hline Yes & $69,997(98.85)$ & $70,389(98.64)$ \\
\hline No & $812(1.15)$ & $971(1.36)$ \\
\hline \multicolumn{3}{|l|}{ Family history of breast cancer } \\
\hline Yes & $517(0.70)$ & $504(0.68)$ \\
\hline No & $73,310(99.30)$ & $74,050(99.32)$ \\
\hline \multicolumn{3}{|c|}{ Previous consultation for breast-related complaints } \\
\hline Yes & $882(1.21)$ & $785(1.06)$ \\
\hline No & & $73,142(98.94)$ \\
\hline \multicolumn{3}{|c|}{ Previous consultation for gynaecological complaints } \\
\hline Yes & $7,816(10.70)$ & $7,298(9.87)$ \\
\hline No & $65,212(89.30)$ & $66,667(90.13)$ \\
\hline
\end{tabular}

Figures in parentheses are percentages, unless indicated otherwise. The total number of women in each variable category differs as a result of missing information about few participants for the respective variable. History of breast feeding was computed only among women with live births. ${ }^{1}$ Figures in parentheses are SD. and 1.647, respectively, for cervix cancer variables and 0.00013758 and 2.0408, respectively, for breast cancer variables), with $\alpha=$ 0.05 , the study has around $80 \%$ power to detect a $25 \%$ reduction in the incidence and $40 \%$ reduction in mortality due to cervix cancer and a power of $80 \%$ to detect a $30 \%$ reduction in breast cancer mortality.

\section{Statistical Analysis}

Data for this study are recorded in Fox Pro (version 2.5). Checks for consistency and data analysis are carried out at the Tata Memorial Hospital using Stata 8.2. Intracluster correlation and design effect are calculated using MLWin software. The analysis is done on an intention-to-treat basis. In this paper, compliance is evaluated at the following levels: level $1=$ compliance to consent and interviews after invitation to participate in the study among the eligible women from the chosen clusters; level $2=$ ability to trace the women in the follow-up cycles (cohort retention); level $3=$ compliance to participation in screening for women in the intervention arm.

Compliance at levels 1 and 2 is calculated as percentage. The characteristics of compliant and non-compliant women are compared using the $\chi^{2}$ test. The determinants of compliance at level 3 is estimated using Stata software and analysed by univariate and multivariate logistic regression analyses to evaluate the effects of various sociodemographic and reproductive characteristics of women on compliance, by estimating odds ratios and their $95 \%$ confidence intervals. For the multivariate analysis, all variables considered in the univariate analysis were included in the logistic regression model using the stepwise method. Hence, only the results of significant variables that remained in the model are presented in the multivariate analysis.

\section{Results}

Among the 75,360 eligible women invited from the intervention clusters, $311(0.41 \%)$ refused to participate in the trial and among the 76,178 eligible women invited from the control clusters, $181(0.24 \%)$ refused to participate. The participation rates for HEP and screening among the eligible women from the intervention arm and for HEP alone from the control arm are presented in table 2 . The distribution of various sociodemographic variables among the compliers and non-compliers from the intervention arm is presented in table 3. Univariate and multivariate logistic regression analyses were carried out to identify the predictors of participation in screening (table 3). Accordingly, age, community, education, income, language, marital status and history of previous consultation for breast-related or gynaecological complaints emerged as independent predictors of participation in screening in the multivariate logistic regression analysis. Younger women, women from other than Hin$\mathrm{du}$ and Muslim communities, school level-educated women, women belonging to lower-income families, 
Table 2. Compliance to screening in the intervention arm and compliance to health education and surveillance in the control arm

\begin{tabular}{|c|c|c|c|c|c|c|}
\hline \multicolumn{4}{|l|}{ Intervention arm } & \multicolumn{3}{|l|}{ Control arm } \\
\hline Screening rounds & Site & $\begin{array}{l}\text { Eligible } \\
\text { women }\end{array}$ & $\begin{array}{l}\text { Compliance } \\
\text { to screening }\end{array}$ & $\mathrm{HEP} /$ contact rounds & Eligible women & $\begin{array}{l}\text { Compliance to health educa- } \\
\text { tion/surveillance process }\end{array}$ \\
\hline First round (IC 1-10) & $\begin{array}{l}\text { breast } \\
\text { cervix }\end{array}$ & $\begin{array}{l}75,360 \\
71,561^{1}\end{array}$ & $\begin{array}{l}56,985(75.62) \\
51,145(71.47)\end{array}$ & First round (CC 1-10) & 76,178 & $69,227(90.88)$ \\
\hline Second round (IC 1-10) & $\begin{array}{l}\text { breast } \\
\text { cervix }\end{array}$ & $\begin{array}{l}71,500^{2} \\
66,219^{1}\end{array}$ & $\begin{array}{l}49,012(68.55) \\
41,354(62.45)\end{array}$ & Second round (CC 1-10) & $72,145(5.29)^{2}$ & $62,755(86.98)$ \\
\hline Third round (IC 1-10) & $\begin{array}{l}\text { breast } \\
\text { cervix }\end{array}$ & $\begin{array}{l}67,530^{2} \\
61,108^{1}\end{array}$ & $\begin{array}{l}47,133(69.80) \\
36,643(59.96)\end{array}$ & Third round (CC 1-10) & $67,664(6.21)^{2}$ & $59,543(88.00)$ \\
\hline
\end{tabular}

Figures in parentheses are percentages of eligibles. IC $=$ Intervention cluster; $\mathrm{CC}=$ control cluster.

${ }^{1}$ Less women are eligible for cervix than for breast screening because $3,799(5.04 \%)$ women in round $1,5,281(7.01 \%)$ in round 2 and $6,422(8.52 \%)$ women in round 3 underwent hysterectomy.
${ }^{2}$ There is $5.12 \%$ attrition between rounds 1 and 2 and $5.55 \%$ attrition between rounds 2 and 3 in the intervention arm. Similarly, there is $5.29 \%$ attrition between rounds 1 and 2 and $6.21 \%$ attrition between rounds 2 and 3 in the control arm because of expired and shifted women who could not be traced.
Marathi-speaking women, married women and women who had previously consulted for any breast or gynaecological complaints had higher compliance to participation in screening.

The compliance to HEP, which was offered only in the first round, in the control arm was $90.88 \%$. The compliance to screening in the intervention arm was $76 \%$ for breast examination and $71.5 \%$ for cervix examination in the first round. There was 5.2\% attrition (5.12\% in the intervention arm and 5.29\% in the control arm) in the second round and $5.88 \%$ attrition $(5.55 \%$ in the intervention arm and $6.21 \%$ in the control arm) in the third round because of permanent loss of eligible women from the trial. Change in residence (which in some cases could not be traced in spite of all the efforts by the MSW) and death of the enrolled women accounted for this attrition. In addition, 20,766 women in the second cycle and 16,625 women in the third cycle were temporarily unavailable, and hence could not be invited. The attrition rate in the present trial is relatively low because of the additional efforts of project staff to trace the shifted women to their new residence. This attrition rate is quite conducive for long-term retention of the cohort. The average compliance till the end of the third screen is $71.43 \%$ for women participating in breast cancer screening and $64.93 \%$ for women participating in cervix cancer screening. Of the eligible women in the intervention arm, 70,652 (93.75\%) were screened at least once, 53,017 (70.35\%) twice and 29,461 (39.09\%) were screened thrice for breast cancer. For cervix cancer screening, $63,064(88.13 \%)$ of the eligible women in the intervention arm were screened at least once, 43,465 $(60.74 \%)$ twice and 22,611 (31.60\%) thrice. Women who were screened positive for breast cancer had lower compliance to screening in future screening rounds. Only $66.59 \%$ of the women previously screened positive participated in follow-up screening (average participation is $71.43 \%$ ). On the other hand, women screened positive for cervix cancer had higher participation in future screening rounds $(70.06 \%$ among screen positives participated in follow-up screening compared to the average participation of $60.24 \%$ ). Of the women with previous false-positive screening test results, $69.51 \%$ also participated in future screening rounds.

\section{Discussion}

In the present paper, the compliance to screening at the community level is discussed. This is followed by another paper [Dinshaw et al., this issue, pp 154-161] discussing the compliance to further diagnostic investigations and treatment, which are interventions at the nodal hospital. Identifying the different reasons for non-compliance and undertaking corrective measures wherever feasible determines the success of screening.

In the present trial, some of the enrolled women could not be traced in the second round because of shift of residence. In order to avoid any further attrition in the subsequent rounds, a corrective measure in the form of distributing self-addressed and stamped postcards to the eligible women was undertaken, with instructions 
Table 3. Distribution of compliers and non-compliers to screening in the intervention arm by important sociodemographic variables and the results of univariate and multivariate logistic regression analyses identifying predictors of compliance to breast and cervix cancer screening

\begin{tabular}{|c|c|c|c|c|c|c|c|c|}
\hline \multirow[t]{2}{*}{ Variables } & \multirow{2}{*}{$\begin{array}{l}\text { Eligible } \\
\text { women }\end{array}$} & \multirow{2}{*}{$\begin{array}{l}\text { Compliers to } \\
\text { screening, } \%\end{array}$} & \multicolumn{3}{|c|}{ Univariate analysis } & \multicolumn{3}{|c|}{ Multivariate analysis } \\
\hline & & & OR & $95 \% \mathrm{CI}$ & $\mathrm{p}$ value & OR & $95 \% \mathrm{CI}$ & $\mathrm{p}$ value \\
\hline \multicolumn{9}{|l|}{ Age groups } \\
\hline $35-39$ years & 22,718 & 94.74 & 1 & & 0.000 & 1 & & 0.000 \\
\hline $40-44$ years & 17,311 & 94.26 & 0.911 & $0.836-0.994$ & 0.036 & 0.904 & $0.827-0.987$ & 0.025 \\
\hline $45-49$ years & 14,183 & 94.56 & 0.965 & $0.879-1.059$ & 0.447 & 0.949 & $0.862-1.044$ & 0.281 \\
\hline $50-54$ years & 9,422 & 93.63 & 0.816 & $0.738-0.903$ & 0.000 & 0.798 & $0.718-0.887$ & 0.000 \\
\hline $55-59$ years & 6,049 & 92.41 & 0.676 & $0.605-0.756$ & 0.000 & 0.677 & $0.601-0.762$ & 0.000 \\
\hline $60-64$ years & 5,270 & 91.80 & 0.622 & $0.555-0.697$ & 0.000 & 0.620 & $0.546-0.704$ & 0.000 \\
\hline$\geq 65$ years & 224 & 87.95 & 0.405 & $0.270-0.608$ & 0.000 & 0.423 & $0.271-0.660$ & 0.000 \\
\hline \multicolumn{9}{|l|}{ Community } \\
\hline Hindu & 58,449 & 94.45 & 1 & & 0.000 & 1 & & 0.000 \\
\hline Muslim & 9,746 & 91.83 & 0.660 & $0.609-0.716$ & 0.000 & 0.937 & $0.854-1.027$ & 0.166 \\
\hline Others & 6,844 & 94.75 & 1.061 & $0.949-1.187$ & 0.299 & 1.266 & $1.127-1.424$ & 0.000 \\
\hline \multicolumn{9}{|l|}{ Occupation } \\
\hline Housewife & 66,490 & 94.11 & 1 & & 0.000 & & & \\
\hline Service & 3,840 & 94.69 & 1.115 & $0.964-1.288$ & 0.142 & & & \\
\hline Manual laborer & 4,718 & 94.96 & 1.177 & $1.029-1.346$ & 0.017 & & & \\
\hline \multicolumn{9}{|l|}{ Education } \\
\hline Illiterate & 29,512 & 93.05 & 1 & & 0.000 & 1 & & 0.000 \\
\hline School level & 44,760 & 95.01 & 1.420 & $1.335-1.511$ & 0.000 & 1.284 & $1.201-1.373$ & 0.000 \\
\hline Graduates & 778 & 91.26 & 0.779 & $0.605-1.004$ & 0.053 & 0.776 & $0.599-1.003$ & 0.053 \\
\hline \multicolumn{9}{|c|}{ Monthly per capita income } \\
\hline$\leq 500$ rupees & 35,394 & 94.60 & 1 & & 0.000 & 1 & & 0.000 \\
\hline$>500$ rupees & 39,617 & 93.85 & 0.871 & $0.819-0.927$ & 0.000 & 0.803 & $0.753-0.856$ & 0.000 \\
\hline \multicolumn{9}{|l|}{ Language } \\
\hline Marathi & 42,704 & 95.45 & 1 & & 0.000 & 1 & & 0.000 \\
\hline Hindi & 12,883 & 92.89 & 0.622 & $0.574-0.675$ & 0.000 & 0.646 & $0.592-0.705$ & 0.000 \\
\hline Others & 19,508 & 92.15 & 0.559 & $0.522-0.599$ & 0.000 & 0.576 & $0.532-0.623$ & 0.000 \\
\hline \multicolumn{9}{|l|}{ Marital status } \\
\hline Single & 295 & 85.08 & 1 & & 0.000 & 1 & & 0.000 \\
\hline Married & 61,582 & 94.41 & 2.963 & $2.147-4.089$ & 0.000 & 2.840 & $2.049-3.935$ & 0.000 \\
\hline Widowed/divorced & 12,682 & 93.16 & 2.389 & $1.721-3.315$ & 0.000 & 2.692 & $1.928-3.758$ & 0.000 \\
\hline \multicolumn{9}{|c|}{ Previous consultation for breast or gynaecological complaints } \\
\hline No & 66,866 & 93.59 & 1 & & 0.000 & 1 & & 0.000 \\
\hline Yes & 8,494 & 95.70 & 1.463 & $1.311-1.633$ & 0.000 & 1.527 & $1.367-1.706$ & 0.000 \\
\hline \multicolumn{9}{|c|}{ Family history of breast cancer } \\
\hline Yes & 517 & 92.26 & 1 & & 0.000 & & & \\
\hline No & 73,310 & 94.12 & 0.745 & $0.538-1.029$ & 0.074 & & & \\
\hline
\end{tabular}

The odds ratio (OR) for trend for age when considered continuous is 0.981 with a $95 \%$ confidence interval (CI) of $0.977-0.985$.

to write their new address and mail the postcards in case of shifting residence. Many women responded to this and thus could be traced from round 3 onwards. Hence, the attrition rate did not increase greatly after round 2 as shown in table 2 , in spite of many women shifting to new residence. Women from the control arm were not offered screening but were invited to participate in the
HEP. There is higher compliance to participation among women in the control arm compared to the intervention arm, which indicates that it is easier to motivate people to participate in the HEP than the actual screening process. Considering that the population was never exposed to breast and cervix cancer information and screening prior to this study, compliance rates of $76 \%$ for breast 
cancer screening and 71.5\% for cervix cancer screening in the first round can be considered as fairly good. The initial compliance in the 5 published large randomised controlled trials for breast cancer screening with mammography range from $61 \%$ in Edinburgh to $89 \%$ in a Swedish 2-county trial [11]. The average participation rate was $71.6 \%$ during the 10 years of follow-up for mammography in Sweden [12]. Compliance rates for screening have varied in different cervical cancer screening trials in India from 56.4 to $79 \%$ [13-16]. Compared to the first round, participation is lower in the follow-up rounds in the present trial. Several studies have shown that the high compliance rates in the initial screening round decline with every new future screening round $[7$, 17-21].

In our study, increasing age, women belonging to the Muslim community, women with higher education, higher-income women, women speaking a language other than Hindi and Marathi, single unmarried women and women with no history of previous consultation for breast-related or gynaecological complaints were identified as predictors for non-compliance to screening. Increasing age was a strong predictor for non-participation in several studies $[14,22-25]$. Lower participation in screening was observed among unmarried, divorced or widowed women and among those living in cramped housing [25]. Educational level had variable impacts, lower income had a negative impact and type of occupation showed no relation with participation $[24,25]$. In the present study, women educated up to school level had the best compliance followed by illiterates, whereas graduate women had poor compliance. This could be because graduate women may prefer to get themselves screened in a private clinic set-up rather than a camp environment. Women belonging to lower-income families participated more frequently compared to women from high-income families. Marathi being the local language and Hindi the national language, health talk and counselling was offered in these two languages and hence the compliance is better among women speaking these languages compared to others. Screening behaviour was found to have varied association with race/ethnicity [17, 24]. Several studies have shown that encouragement by the women's spouses, family, friends and physicians increases the likelihood of women participating in the screening trial [17, $26,27]$, whereas poor trust in health care was associated with non-participation [27]. In cervical cancer screening programmes in Chile, Costa Rica and Cuba, $80-85 \%$ of the eligible women were screened at least once [28]. In Sweden, participation in mammography was more than
$50 \%$ at all 5 rounds with only $8.5 \%$ remaining as permanent non-participants [12]. In an oral cancer screening trial in South India, involving 3 rounds of screening, 91\% were screened at least once, $55 \%$ twice and $30 \%$ thrice [29]. The present trial records high compliance rates, with 94 and $84 \%$ of the eligible women being screened at least once for breast and cervix cancer, respectively, at the end of 3 screening rounds. In the present study, the screening participation is lower for cervix than for breast examinations.

The present trial indicates that there is good acceptance of screening for breast and cervix cancers by the methods of CBE and VIA, respectively. The initial results of a randomised controlled trial in rural South India also indicated that VIA-based screening programmes are feasible, safe and acceptable to the rural population [30]. The results of a screening trial (whether beneficial or detrimental) are an underestimate of the likely effects of screening in the general population, since the effects that are evaluated take place in those who accept the screening (compliers) among those who were offered screening [11]. The present trial demonstrates good compliance to screening. Similar compliance rates are not likely to be reproducible to the same extent in a screening programme where it may not be feasible to recruit staff dedicated only to the screening of cancers. Comparing the Malmo Mammographic Service Screening Programme with the corresponding trial demonstrates more attendance $(74 \%)$ in the trial compared to the programme (65\%) [25]. Thus, the compliance achieved in a trial setting is always better than that of a screening programme. Nevertheless, our trial covered $11.5 \%$ of the target population in Mumbai [31] and hence the practicability of implementing a screening programme in an urban community in India and South Asia for breast and cervix cancer screening among women is demonstrated by this trial. Choosing a suitable screening test is only one aspect of a screening programme. A more challenging issue is the organisation of the programme in its totality and acceptance of the programme by the community, which is aptly demonstrated in this trial. We may conclude that organising a screening programme for common cancers using lowcost effective technology is feasible and acceptable to the Indian population, if organised in a community setting in proximity to their residence, by incorporating health education before screening and with special efforts for cohort retention. 


\section{Acknowledgements}

The present study was conducted mainly through funding support by the RO1 grant of the National Cancer Institute and with the intramural Tata Memorial Hospital funds. The Sir Dorabji Tata Trusts, Sir M.K. Tata Trusts and the Women's Cancer Initiative partly covered the patient care costs. We especially acknowledge Dr. Indraneel Mittra, who was associated with this study from September 1997 to July 2002 as the principal investigator. The authors wish to acknowledge the contributions of the following persons who were associated with the study in various capacities at different times during the progress of the study: An- thony Miller, Perin Notani, Daniel E. E, Vani Parmar, Mandar Nadkarni, Hemant Tongaonkar, Amita Maheshwari, Richard Muwonge, Rajesh Dixit, Pratiksha Namjoshi, Shalini Singh, Sangita Aranke, Rajmati Pilankar, Sharmila Pimple, Subita Patil, Malliga Subramanian, Deepali Kadam, Vidula Bhole, Swapna Patil, Chaitali Patil and all the staff working for this project. We thank the participants of the project, their families, the local community leaders, the Mumbai Cancer Registry and the Brihanmumbai Municipal Corporation for sharing their data. The authors thank the independent data safety and monitoring committee consisting of Rengasamy Sankaranarayanan, Prakash Gupta and Vendhan Gajalakshmi for their guidance.

\section{References}

1 Dinshaw KA: Addressing the cancer agenda: How have we measured up?; in Agarwal SP, Rao YN, Gupta S (eds): Fifty Years of Cancer Control in India. South Delhi, NCCP, DGHS, Ministry of Health and Family Welfare, 2002, pp 14-21. http://mohfw.nic.in/ pg14to21.pdf

2 Nandkumar A, Ramnath T, Roselind FS, Shobana B, Prabhu K: Two-Year Report of the Population Based Cancer Registries 1999-2000. Bangalore, National Cancer Registry Programme, Indian Council of Medical Research, 2005. http://www.icmr. nic.in/ncrp/1999-00/PBCR\%20Report \%201999_00.pdf

-3 Sankaranarayanan R, Basu P, Ramani S, Wesley R, Cedric M, Keita N, Gombe CC, Sharma R, Dolo A, Shastri S, Nacoulma M, Nayama M, Somanathan T, Lucas E, Muwonge R, Frappart L, Parkin DM: Accuracy of visual screening for cervical neoplasia: results from an IARC multicentre study in India and Africa. Int J Cancer 2004;110:907913.

-4 University of Zimbabwe/JHPIEGO Cervical Cancer Project: Visual inspection with acetic acid for cervical cancer screening: test qualities in a primary-care setting. Lancet 1999;353:869-873.

5 Belinson JL, Pretorius RG, Zhang WH, Wu LY, Qiao YL, Elson P: Cervical cancer screening after simple visual inspection after acetic acid. Obstet Gynecol 2001;98:441-444.

6 Mittra I: Breast screening: the case for physical examination without mammography. Lancet 1994:343:342-344.

7 Miller AB, To T, Baines CJ, Wall C: The Canadian National Breast Screening Study. 2. 13 -year results of a randomized trial in women aged 50-59 years. J Natl Cancer Inst 2000; 92:1490-1499.

8 Basset AA: Physical examination of the breast and breast self-examination; in Miller $\mathrm{AB}$ (ed): Screening for Cancer. Orlando, Academic Press, 1985.
9 Sankaranarayan R, Wesley R: A Practical Manual on Visual Screening for Cervical Neoplasia. IARC Technical Publication No. 41. Lyon, IARC Press, 2003.

10 Sellors J, Sankaranarayanan R: Colposcopy and Treatment of Cervical Intraepithelial Neoplasia: A Beginner's Manual. Lyon, IARC Press, 2003.

11 Elwood JM, Cox B, Richardson AK: The effectiveness of breast cancer screening by mammography in younger women. Online J Curr Clin Trials 1993;32.

12 Tornberg S, Kemetli L, Svane G, Rosen M, Stenbeck M, Nystrom L: Pattern of participation in a cohort aged 50-60 years at first invitation to the service-screening programme with mammography in Stockholm county, Sweden. Prev Med 2005;41:728-733.

13 Nene BM, Deshpande S, Jayant K, Budukh AM, Dale PS, Deshpande DA, Chiwate AS, Malvi SG, Deokar S, Parkin DM, Sankaranarayanan R: Early detection of cervical cancer by visual inspection: a population-based study in rural India. Int J Cancer 1996;68: 770-773.

14 Sankaranarayanan R, Rajamanickam R, Arrossi S, Theresa R, Esmy PO, Mahe $\mathrm{C}, \mathrm{Mu}$ wonge R, Parkin DM, Cherian J: Determinants of participation of women in a cervical cancer visual screening trial in rural south India. Cancer Detect Prev 2003;27:457-465.

15 Sankaranarayanan R, Nene BM, Dinshaw KA, Cedric M, Jayant K, Shastri SS, Malvi SG, Chinoy R, Kelkar R, Budukh AM, Keskar V, Rajeshwarker R, Muwonge R, Kane S, Parkin DM: A cluster randomized controlled trial of visual, cytology and human papillomavirus screening for cancer of the cervix in rural India. Int J Cancer 2005;116:617-623.

16 Sankaranarayanan R, Nene BM, Dinshaw K, Rajkumar R, Shastri S, Wesley R, Basu P, Sharma R, Thara S, Budukh A, Parkin DM: Early detection of cervical cancer with visual inspection methods: a summary of completed and on-going studies in India. Salud Publica Mex 2003;45(suppl 3):S399-S407.
17 Howe HL: Repeat mammography among women over 50 years of age. Am J Prev Med 1992;8:182-185.

18 Bjurstam N, Bjorneld L, Warwick J, Sala E, Duffy SW, Nystrom L, Walker N, Cahlin E, Eriksson O, Hafstrom LO, Lingaas H, Mattsson J, Persson S, Rudenstam CM, Salander $\mathrm{H}$, Save-Soderbergh J, Wahlin T: The Gothenburg Breast Screening Trial. Cancer 2003;97:2387-2396.

19 Miller AB, Baines CJ, To T, Wall C: Canadian National Breast Screening Study. 1. Breast cancer detection and death rates among women aged 40 to 49 years. CMAJ 1992;147: 1459-1476.

20 Thomas DB, Gao DL, Self SG, Allison CJ, Tao Y, Mahloch J, Ray R, Qin Q, Presley R, Porter P: Randomized trial of breast self-examination in Shanghai: methodology and preliminary results. J Natl Cancer Inst 1997; 89:355-365.

21 Roberts MM, Alexander FE, Anderson TJ, Chetty U, Donnan PT, Forrest P, Hepburn W, Huggins A, Kirkpatrick AE, Lamb J, Muir $\mathrm{BB}$, Prescott RJ: Edinburgh trial of screening for breast cancer: mortality at seven years. Lancet 1990;335:241-246.

22 Philip J, Harris WG, Flaherty C, Joslin CAF, Rustage JH, Wijesinghe DP: Breast self-examination: clinical results from a population-based prospective study. Br J Cancer 1984;50:7-12.

23 Matson S, Andersson I, Berglund G, Janzon L, Manjer J: Non-attendance in mammographic screening: a study of intra-urban differences from the city of Malmö in Sweden 1990-1994. Cancer Detect Prev 2001;25: 132-137.

24 Leyden WA, Manos MM, Geiger AM, Weinmann S, Mouchawar J, Bischoff K, Yood MU, Gilbert J, Taplin SH: Cervical cancer in women with comprehensive health care access: attributable factors in the screening process. J Natl Cancer Inst 2005;97:675683. 
-25 Zackrisson S, Andersson I, Manjer J, Janzon L: Non-attendance in breast cancer screening is associated with unfavourable socioeconomic circumstances and advanced carcinoma. Int J Cancer 2004;108:754-760.

-26 Baines CJ, To T, Wall C: Women's attitudes to screening after participation in the national breast screening study. Cancer 1990; 65:1663-1669.

-27 Lagerlund M, Hedin A, Sparén P, Thurfjell E, Lambe M: Attitudes, beliefs, and knowledge as predictors of nonattendance in a Swedish population-based mammography screening program. Prev Med 2000;31:417-428.
28 Sankaranarayanan R, Budukh A, Rajkumar $\mathrm{R}$ : Effective screening programmes for cervical cancer in low- and middle-income developing countries. Bull World Health Organ 2001;79:954-962.

29 Sankaranarayanan R, Ramadas K, Thomas G, Muwonge R, Thara S, Mathew B, Rajan B: Effect of screening on oral cancer mortality in Kerala, India: a cluster-randomised controlled trial. Lancet 2005;365:1927-1933.
30 Sankaranarayanan R, Rajkumar R, Theresa R, Esmy PO, Mahe C, Bagyalakshmi KR, Thara S, Frappart L, Lucas E, Muwonge R, Shanthakumari S, Jeevan D, Subbarao TM, Parkin DM, Cherian J: Initial results from a randomized trial of cervical visual screening in rural South India. Int J Cancer 2004;109: 461-467.

31 Yeole BB, Jussawalla DJ, Sabnis SD, Sunny L: Survival from breast and cervical cancers in Mumbai (Bombay), India; in Sankarnarayanan et al. (ed): Cancer Survival in Developing Countries. IARC Scientific Publication No. 145. Lyon, IARC, 1998, pp 79-90. 